\title{
Право человека на здоровье как объект международно-правового регулирования
}

Борисова-Жарова В.Г.

Эффективное обеспечение права человека на здоровье с юридической точки зрения возможно только при наличии отлаженного работоспособного механизма реализации норм, регулирующих отношения в данной области. Поскольку проблемы здравоохранения давно перешагнули через государственные границы и приобрели универсальный характер, в ответ на вызовы времени международное право выработало целую совокупность правил, стандартов и предписаний, призванных решить международные проблемы в сфере отношений по обеспечению здоровья.

За достаточно длительный период, прошедший с момента провозглашения права человека на здоровье во Всеобщей декларации прав человека (1948), совокупность норм в этой области эволюционировала, приобрела определенную внутреннюю структуру и иерархию. Положения международных актов регулируют самые разные вопросы в области здоровья - от профилактики и предотвращения эпидемий и пандемий до этических проблем, связанных с вмешательством медицины в жизнь человека. Все это дает возможность констатировать появление комплексного международно-правового института права человека на здоровье.

Объем же права на здоровье состоит из тех элементов, которые содержатся в различных международных соглашениях, устанавливающих право на здоровье. Объем права на здоровье является, соответственно, и его содержанием. Для начала все эти элементы можно разделить на две категории, посвященные «охране здоровья» и «основным предпосылкам здоровья» ${ }^{1}$.

\footnotetext{
* Борисова-Жарова Виктория Геннадьевна - аспирант кафедры международного права Дипакадемии РФ.

${ }^{1}$ См.: Такое разделение также использовалось в исследовании РАНО 1989 г. С. 644. Согласно данному исследованию, право на здоровье состоит из двух компонентов - права на здоровые условия проживания (традиционные объекты интереса общественного здравоохранения - чистые вода и воздух, наличие систем канализации, контроль за инфекционными заболеваниями, осуществляемый путем поддержания соответствующих санитарных условий, проведения вакцинаций и образовательных программ), и права
} 
На международном уровне не существует общего стандартного определения_«охраны здоровья». Обычная концепция «охраны здоровья» - понятие более широкое, чем медицинская (врачебная) помощь, то есть помощь, предоставляемая профессиональными врачами ${ }^{2}$. Медицинская помощь включает в себя также парамедицину (деятельность медицинских сестер, занимающихся уходом на дому, и лиц, оказывающих непрофессиональную врачебную помощь, например повитух). Понятие охраны здоровья шире понятия медицинской помощи, поскольку оно включает в себя профилактическую охрану здоровья.

ВО3, кроме первичной охраны здоровья, выделяет охрану здоровья второго и третьего уровней. Охрана здоровья - это помощь на частном уровне, которая включает в себя среди прочего помощь матерям и детям, предотвращение и контроль над локальными эндемическими заболеваниями, иммунизацию от основных инфекционных болезней, а также необходимое лечение различных заболеваний и травм. Охрана здоровья второго уровня носит более специализированный характер и включает в себя, например, рентгеновскую диагностику, общую хирургию, уход за женщинами с тяжело протекающей беременностью или послеродовыми осложнениями. Охрана здоровья третьего уровня еще более специализирована и включает в себя, например, нейро- и кардиохирургию.

Кроме того, ВОЗ проводит различие между укреплением здоровья 3 , защитой здоровья ${ }^{4}$ и предотвращением заболеваний. В то время как первичная профилактика ставит своей целью предотвратить возникновение болезни, задачей вторичной профилактики является борь-

на «охрану здоровья» (обычно охрана здоровья отождествляется с врачебной помощью, направленной на предотвращение заболеваний и восстановление здоровья конкретного человека, а не на социальное здравоохранение).

2 См. также: Чайлдресс, 1979 г. с 134, сноска 1, Холтраст, Хендрикс и Воден, 1996 г. c. 40. Линен, 1991 г. на с. 31 дает такое определение охране здоровья: «Вся система охраны здоровья на дому, в медицинских учреждениях и за их пределами, включая профессиональную врачебную помощь, администрирование и финансирование соответствующих институтов».

3 Укрепление здоровья подразумевает пропаганду здорового образа жизни и развитие социальных, экономических, экологических и личных факторов, влияющих на здоровье (например, пробуждение у людей заинтересованности следить за состоянием своего здоровья и обучение их тому, как следует решать те или иные проблемы в этой области).

4 Защита здоровья подразумевает, что люди защищены от потенциальных угроз для своего здоровья, что означает, например, принятие мер по обеспечению безопасности на рабочем месте. 
ба с уже возникшим заболеванием. Его развитие нужно замедлить или прекратить путем как можно более раннего выявления и лечения, сокращения частоты повторных вспышек заболевания и возникновения хронических патологий с помощью реабилитационных мер, коррекционной хирургии и обеспечения протезами. Улучшение и защита здоровья, а также предотвращение заболеваний частично выходят за рамки охраны здоровья и относятся, скорее, косновополагающим предпосылкам здоровья», так как в них содержатся такие элементы, как пропаганда здоровья, социальная поддержка, улучшение питания и санитарных условий. Основополагающие предпосылки здоровья также включают в себя доступ к чистой воде, надлежащее удаление отходов жизнедеятельности человека, пищу, здоровую окружающую среду, нормальные условия труда, доступ к информации, касающейся здоровья.

Предпосылками здоровья признаны также мир, жилье, образование, продовольствие, доход, устойчивая экосистема, возобновляемые средства, социальная справедливость, равноправие.

В подпункте 12(2)(d) Международного пакта об экономических, социальных и культурных правах говорится о «предотвращении, лечении и контроле» за заболеваниями, что выходит далеко за рамки первичной охраны здоровья, равно как и за рамки профилактической медицины. Этого нельзя сказать о статье 12 Конвенции о ликвидации всех форм дискриминации в отношении женщин, где практически не упомянуты основополагающие предпосылки здоровья и речь идет почти исключительно об охране здоровья. Английская версия подпункта (2) (d) статьи 12 Международного пакта об экономических, социальных и культурных правах несколько шире, чем французская и нидерландская версии. Если в английской версии говорится об обязательстве государства обеспечивать равный доступ к службам охраны здоровья, то в двух других речь идет просто об обеспечении медицинской помощью (services medicaux и medische zorg). В соответствии со статьей 33(4) Венской конвенции о праве международных договоров 1969 года, в случае подобных разночтений в первую очередь необходимо провести их текстуальный анализ, принимая во внимание предмет и цель договора. Широкое по своей сути обязательство, содержащееся в первой фразе статьи 12(1) Конвенции о ликвидации всех форм дискриминации в отношении женщин ${ }^{5}$ (ликвидация дискриминации в от-

5 Конвенция о ликвидации всех форм дискриминации в отношении женщин принята и открыта для подписания, ратификации и присоединения резолюцией Генеральной 
ношении женщин в области охраны здоровья), побуждает нас трактовать второй пункт этой статьи как говорящий обо всем объеме охраны здоровья, а не только о медицинской помощи.

Во втором пункте статьи 12(1) Конвенции о ликвидации всех форм дискриминации в отношении женщин упомянуты службы по планированию семьи. О необходимости обеспечения доступа к этим службам подробнее говорится во втором пункте, который устанавливает, что женщины имеют право на «соответствующее обслуживание в период беременности, родов и послеродовой период, предоставление, когда это необходимо, бесплатных услуг, а также соответствующее питание в период беременности и кормления».

В статье 24(1) Конвенции о правах ребенка ${ }^{6}$ говорится о доступе к службам охраны здоровья, которые описываются как «средства лечения болезней и восстановления здоровья». Подпункт 2(b) упоминает «медицинскую помощь и охрану здоровья».

Попытаемся далее систематизировать данные права по определенным критериям. Но прежде чем приступать к анализу норм, образующих данный институт, напомним, что право на здоровье - понятие неоднородное, собирательное, отражающее определенную совокупность индивидуальных субъективных прав.

Анализ международных документов, регулирующих отношения в сфере права человека на здоровье, показывает, что право на здоровье включает в себя следующие виды субъективных прав:

- право на гарантированный доступ к системе охраны здоровья 7 ;

Ассамблеи 34/180 от 18 декабря 1979 года. Вступила в силу 3 сентября 1981 года. СССР подписал Конвенцию 17.07.1980 с оговоркой и ратифицировал (Указ Президиума ВС СССР от 19.12.1980 № 3565-Х). Ратификационная грамота сдана на хранение Генеральному секретарю ООН 23.01.1981. Позже СССР снял оговорку по пункту 1 ст. 29 (Указ Президиума ВС СССР от 10.02.1989 № 10125-ХI). Федеральный закон от 19.06.2004 № 52-Ф3 «О ратификации факультативного протокола к Конвенции о ликвидации всех форм дискриминации в отношении женщин» (принят ГД ФС РФ 02.06.2004).

${ }^{6}$ Конвенция о правах ребенка принята резолюцией 44/25 Генеральной Ассамблеи от 20 ноября 1989 г. Вступила в силу 2 сентября 1990 г. Ратифицирована Верховным Советом СССР 13 июля 1990 г. Вступила в силу для СССР 15 сентября 1990 г.

7 На наш взгляд, удачным является определение охраны здоровья, содержащееся в ст. 1 Основ законодательства РФ об охране здоровья граждан. В соответствии с ним охрана здоровья граждан - это совокупность мер политического, экономического, правового, социального, культурного, научного, медицинского, санитарно-гигиенического и противоэпидемического характера, направленных на сохранение и укрепление физического 
- право на информацию о факторах, влияющих на здоровье;

- право на медико-социальную помощь.

Право на доступ к системе охраны здоровья. Данное право является первым и наиболее важным из указанных прав. Оно закреплено во многих международно-правовых документах, в частности в Европейской социальной хартии (пересмотренной) 1996 года (ETS №163) ${ }^{8}$, которая в качестве одной из целей своей политики предусмотрела создание условий, обеспечивающих эффективную реализацию права каждого человека пользоваться любыми средствами, позволяющими достичь наивысший достижимый уровень здоровья (пункт 11 части I). Непосредственно праву на здоровье посвящена статья 11 Хартии, закрепляющая конкретные меры, которые государства-участники должны осуществлять непосредственно либо в процессе сотрудничества с публичными или частными организациями.

Право на доступ к системе охраны здоровья возможно только при наличии указанной системы. Европейский комитет по социальным правам (ранее - Комитет независимых экспертов) ${ }^{9}$ конкретизировал это обязательство, указав, что для его выполнения необходимо наличие надлежащей системы здравоохранения, которая финансируется преимущественно из государственного бюджета. Понятие «надлежащая система здравоохранения» предполагает:

- общедоступную государственную систему, позволяющую оказывать необходимую медицинскую помощь всему населению и обеспечивающую профилактику и диагностику заболеваний;

- специальные меры по защите здоровья матерей, детей и престарелых;

и психического здоровья каждого человека, поддержание его долголетней активной жизни, предоставление ему медицинской помощи в случае утраты здоровья.

8 Европейская социальная хартия (пересмотренная) от 3 мая 1996 года, подписана от имени Российской Федерации в городе Страсбурге 14 сентября 2000 г. Справочник. M., 2000.

9 В 1998 году Комитет независимых экспертов Европейской социальной хартии, был переименован, по инициативе самих экспертов, в Европейский комитет по социальным правам (ECSR). Состоит из независимых экспертов, которые участвуют в работе Комитета 6 лет и могут быть переизбраны на второй срок. Функция Комитета заключается в оценке соответствия национальных законов и практики положениям Хартии с юридической точки зрения, в рамках как процедуры докладов, так и процедуры коллективных жалоб. Страны должны предоставлять ежегодный отчет о том, как они следовали стандартам Хартии. 
- общие меры, направленные на борьбу с алкоголизмом и наркоманией, контроль за качеством продуктов питания и состоянием окружающей среды ${ }^{10}$.

В комментариях к Европейской социальной хартии отмечается, что Европейский комитет по социальным правам, осуществляя правовую оценку выполнения государствами обязательств в соответствии с данным пунктом, учитывает следующие аспекты:

- меры по обеспечению медицинских и парамедицинских услуг надлежащего качества, в особенности в отношении уязвимых групп населения;

- мероприятия по обеспечению безопасности продуктов питания, уменьшения загрязнения почвы и воды, защиты от шума;

- лечение определенных заболеваний - СПИДа, психических расстройств, болезней, связанных с курением, наркоманией, алкоголизмом;

- сведения о численности лиц, занятых в санитарных службах, количестве лечебных учреждений и их территориальном размещении ${ }^{11}$.

Право на информацию о факторах, влияющих на здоровье. Данное право, как правило, закреплено в актах внутригосударственного права, но также находит свое отражение и в международно-правовых документах. Так, пункт 2 статьи 11 Европейской социальной хартии предусматривает обязательство договаривающихся сторон предоставлять услуги консультационного и просветительского характера, направленные на укрепление здоровья и здорового образа жизни, а также на развитие личной ответственности за свое здоровье. Соответственно, речь идет о создании системы просвещения в области охраны здоровья. Ключевым элементом для соблюдения данного положения Хартии является введение санитарного просвещения в школах.

Статья 19 Основ законодательства РФ об охране здоровья граждан гласит: «Граждане имеют право на регулярное получение достоверной и своевременной информации о факторах, способствующих сохранению здоровья или оказывающих на него вредное влияние, включая информацию о санитарно-эпидемиологическом благополучии района проживания, рациональных нормах питания, о продукции, работах,

10 См.: Гомьен Д., Харрис Д., Зваак Л. Европейская конвенция о правах человека и Европейская социальная хартия: право и практика. М., 1998. С. 516.

11 См.: Европейская социальная хартия. Справочник. М., 2000. С. 171-172. 
услугах, их соответствии санитарным нормам и правилам, о других факторах. Эта информация предоставляется местной администрацией через средства массовой информации или непосредственно гражданам по их запросам в порядке, устанавливаемом Правительством Российской Федерации» ${ }^{12}$.

Согласно Конвенции о правах человека и биомедицине (полное наименование - Конвенция о защите прав человека и человеческого достоинства в связи с применением достижений биологии и медицины (ETS No. 164)), заключенной в г. Овьедо, Испания, 4 апреля 1997 года, каждый человек имеет право ознакомиться с любой собранной информацией о его здоровье. Это положение распространяется на любую собранную информацию медицинского характера, включая диагноз, прогноз или любой иной факт, относящийся к состоянию здоровья. В то же время должно уважаться и желание лица не быть о нем информированным (пункт 2 статьи 10), поскольку у пациентов могут быть свои основания не желать знать о некоторых аспектах состояния своего здоровья.

Нельзя не остановиться более подробно на вопросах ограничения права на получение информации и права не быть проинформированным. Допустимые ограничения устанавливаются на законодательном уровне и только в интересах больного (пункт 3 статьи 10 Конвенции). Как показывает практика, в некоторых случаях обязанность врача предоставить информацию вступает в коллизию с интересами охраны здоровья пациентов. Это допустимо, если в соответствии с медицинским прогнозом возможен летальный исход, а сообщение подобной информации может самым серьезным образом сказаться на состоянии здоровья пациента. Разрешение этой коллизии относится к сфере внутригосударственного права, что позволяет учесть социальные и культурные особенности конкретной страны. Действия врача, который утаил часть информации либо раскрыл ее с осторожностью, могут быть оправданы «лечебной необходимостью» (пункт 69 Пояснительного доклада к Конвенции).

Возможны и иные ситуации, когда пациенту, не желающему получать какую-либо медицинскую информацию, необходимо узнать определенные сведения о состоянии своего здоровья. Например, сообщение

12 Основы законодательства Российской Федерации об охране здоровья граждан от 22 июля 1993 г. № 5487-1 (с изменениями от 24 декабря 1993 г.; 2 марта 1998 г.; 20 декабря 1999 г.; 2 декабря 2000 г.; 10 января, 27 февраля, 30 июня 2003 г;; 29 июня, 22 августа, 1, 29 декабря 2004 г.; 7 марта, 21, 31 декабря 2005 г.; 2 февраля, 29 декабря 2006 г., 24 июля, 18 октября 2007 г.) 
пациенту о предрасположенности к тому или иному заболеванию может быть единственным способом заставить его дать согласие на проведение эффективного профилактического лечения. При данных обстоятельствах обязанность врача провести лечение вступает в противоречие с правом пациента не быть информированным. Пути урегулирования подобных ситуаций также могут быть определены в национальном праве.

Стремление врача проинформировать пациента о состоянии его здоровья, несмотря на нежелание последнего получить подобную информацию, может быть продиктовано и интересами защиты других лиц, если заболевание пациента представляет опасность для окружающих. Может сложиться и такая ситуация, когда интересы предотвращения опасности для третьих лиц в соответствии с пунктом 1 статьи 26 Конвенции будут иметь приоритет по отношению к правам пациента. Таким образом, задача национального права - установить справедливый баланс между конкурирующими интересами в тех случаях, когда право одного лица не быть проинформированным или сохранить касающуюся его медицинскую информацию в тайне вступает в противоречие с законным интересом другого лица или других лиц в получении соответствующей информации (пункт 70 Пояснительного доклада) ${ }^{13}$.

Право граждан на медико-социальную помощь. При заболевании, утрате трудоспособности и в иных случаях граждане имеют право на медико-социальную помощь, которая включает профилактическую, лечебно-диагностическую, реабилитационную, протезноортопедическую и зубопротезную помощь, а также меры социального характера по уходу за больными, нетрудоспособными и инвалидами, включая выплату пособия по временной нетрудоспособности. Медико-социальная помощь оказывается медицинскими, социальными работниками и иными специалистами в учреждениях государственной, муниципальной и частной систем здравоохранения, а также в учреждениях системы социальной защиты населения.

В Конвенции о защите прав человека и основных свобод 1950 года $^{14}$ данное право не регламентируется. Тем не менее оно находит

13 См.: Стандарты Совета Европы в области прав человека применительно к положениям Конституции Российской Федерации: избранные права. М.: Институт права и публичной политики, 2002. С. 501-502.

14 Европейская Конвенция о защите прав человека и основных свобод (ЕКПЧ) от 4 ноября 1950 года-основополагающий европейский международный договор, к которому 
свое отражение в других документах международного уровня. В частности, согласно Европейскому кодексу социального обеспечения (пересмотренному) от 6 ноября 1990 года (ETS № 139), целью медицинской помощи является сохранение, восстановление или улучшение состояния здоровья лица, его трудоспособности, а также способности удовлетворять личные потребности (пункт 3 статьи 10) 15 .

Европейская социальная хартия (пересмотренная) от 3 мая 1996 года (ETS No. 163) в качестве одного из своих принципов предусматривает право каждого человека, не имеющего достаточных материальных средств, на медицинскую помощь (пункт 13 части I). В соответствии с пунктом 1 статьи 13 части II Хартии, на государства возлагается обязанность обеспечить любому лицу, не имеющему достаточных средств существования и не способному получить их в результате собственных усилий или из других источников, в частности за счет выплат в рамках системы социального обеспечения, соответствующую помощь, а также необходимый уход в случае болезни. Согласно пункту 2 данной статьи, предоставление подобной помощи не должно приводить к ущемлению политических или социальных прав лиц, которым она оказывается. Таким образом, Хартия предусматривает предоставление адресной медицинской помощи тем лицам, которые соответствуют определенным объективным критериям - в нашем случае не имеют достаточных средств для существования.

Согласно пункту 4 статьи 13 Хартии, ее положения должны применяться с учетом обязательств государств, предусмотренных в Европейской конвенции о социальной и медицинской помощи от 11 декабря 1953 года (ETS № 14). Данный документ гарантирует предоставление медицинской и социальной помощи на территории любой из договаривающихся сторон гражданам других государств Совета Европы - участников Конвенции, не имеющим достаточных средств, в таком же объеме, что и гражданам государства пребывания.

Предоставление медицинских услуг регламентируется и в Европейском кодексе социального обеспечения (пересмотренном) от 6 ноября 1990 года (ETS 139). Его действие распространяется на всех

Россия присоединилась в момент вступления в Совет Европы, ратифицировав ЕКПЧ в мае 1998 года.

15 См.: Стандарты Совета Европы в области прав человека применительно к положениям Конституции Российской Федерации: избранные права. М.: Институт права и публичной политики, 2002. С. 499-501. 
работников, включая учеников, и зависимых от них членов их семей, на лиц, занятых экономической деятельностью, и членов их семей, а также на постоянно проживающих в стране (статья 9).

Медицинская помощь, согласно статье 10 Кодекса, предполагает:

- общую и специализированную практическую помощь;

- амбулаторное и стационарное лечение, включая диагностику, тестирование и посещение врача на дому;

- обеспечение необходимыми фармакологическими средствами;

- обслуживание в больницах и других медицинских учреждениях;

- стоматологическую помощь, включая протезирование;

- медицинскую реабилитацию и восстановительное лечение;

- транспортировку больного.

Медицинская помощь осуществляется квалифицированными специалистами, членами юридически признанных профессиональных объединений медицинских работников. В части III Кодекса регламентируется право на получение пособия по болезни в случае утраты трудоспособности в результате заболевания или несчастного случая.

Решением Алчевского городского суда Луганской области Украины от 9 апреля 2001 года с ОАО «Дукатская горно-геологическая компания» в пользу В. в счет возмещения вреда, причиненного здоровью, взыскано 24079 руб. 68 коп. единовременно и 334 руб. 44 коп. ежемесячно, начиная с 6 марта 2001 года, а также компенсация морального вреда в сумме 20000 руб. Этим же решением с ОАО «Дукатская горно-геологическая компания» взыскана государственная пошлина в доход государства в размере 1404 руб. 64 коп. В. обратился в Магаданский областной суд с ходатайством о признании и разрешении принудительного исполнения указанного решения Алчевского городского суда Луганской области Украины от 9 апреля 2001 года на территории Российской Федерации. Определением Магаданского областного суда от 26 декабря 2001 года ходатайство В. было удовлетворено.

Оставляя без изменений вышеуказанный судебный акт, Верховный Суд РФ обратил внимание на неправильное толкование норм международного права ОАО «Дукатская горно-геологическая компания», подавшим частную жалобу. В Определении от 5 марта 2002 года по делу № 93-Г02-1116 Суд указал, что «в соответствии со ст. 6 Конвенции о правовой помощи и правовых отношениях по гражданским, семейным и уголовным делам, заключенной странами - участниками СНГ

16 Настоящий судебный документ опубликован не был. См. архив Верховного Суда РФ. 
в г. Минске 22 января 1993 г. и ратифицированной Российской Федерацией (Федеральный закон от 4 августа 1994 года № 16-Ф3), договаривающиеся стороны оказывают друг другу правовую помощь путем признания и исполнения судебных решений по гражданским делам. В соответствии со статьей 20 Конвенции, если в частях II-V раздела 2 не установлено иное, иски к юридическим лицам предъявляются в суды договаривающейся стороны, на территории которой находится орган управления юридического лица, его представительство либо филиал. Исходя из этих положений Конвенции, со ссылкой на ее статью 42, в соответствии с которой «обязательства о возмещении вреда, кроме вытекающих из договора и других правомерных действий, определяются по законодательству договаривающейся стороны, на территории которой имело место действие или иное обстоятельство, послужившее основанием для требования о возмещении вреда, по этим делам компетентен суд договаривающейся стороны, на территории которой имело место действие или иное обстоятельство, послужившее основанием для требования о возмещении вреда». В связи с тем, что ОАО «Дукатская горно-геологическая компания» расположено в Российской Федерации, ее представитель в частной жалобе отмечает, что суд Украины по месту жительства истца был некомпетентен рассматривать дело по иску о возмещении вреда здоровью к российскому предприятию. Этот довод основан на неправильном толковании норм процессуального права, содержащихся в международных соглашениях, участниками которых являются Российская Федерация и Украина. В статье 42 Конвенции о правовой помощи и правовых отношениях по гражданским, семейным и уголовным делам (г. Минск, 22 января 1993 года) содержится специальная оговорка о том, что обязательства о возмещении вреда определяются по законодательству договаривающейся стороны, на территории которой имело место действие или иное обстоятельство, послужившее основанием для требования о возмещении вреда, кроме обязательств, вытекающих из договора и других правомерных действий. В данном случае основанием для возмещения вреда по заявлению истца явилось увечье, которое он связывает с необеспечением работодателем безопасных условий труда в период нахождения его в трудовых отношениях с ответчиком. Таким образом, обязательство по возмещению вреда здоровью истца вытекает из трудового договора с российским предприятием-ответчиком, которое истец связывает с ненадлежащим исполнением ответчиком обязательства по этому 
договору в части обеспечения безопасных условий труда. С учетом особой важности социальной защиты лиц, получивших трудовое увечье, профессиональное заболевание либо иное повреждение здоровья, связанные с исполнением ими трудовых обязанностей, и исходя из необходимости урегулирования вопросов в области социальной защиты граждан своих государств Россия, Украина и ряд других государств приняли участие в Соглашении о взаимном признании прав на возмещение вреда, причиненного работникам увечьем, профессиональным заболеванием либо иным повреждением здоровья, связанным с исполнением ими трудовых обязанностей (Москва, 9 сентября 1994 года), утвержденном Постановлением Правительства РФ от 26 июня 1995 года № 616). В соответствии со статьей 8 этого Соглашения по делам, предусмотренным в настоящем Соглашении, компетентен суд стороны, на территории которой имело место действие, послужившее основанием для требования о возмещении вреда, или суд стороны, на территории которой проживают лица, имеющие право на возмещение вреда, по выбору пострадавшего. С учетом этой нормы специального международно-правового обязательства Российской Федерации по делам о возмещении вреда, причиненного работникам увечьем, профессиональным заболеванием либо иным повреждением здоровья, связанным с исполнением ими трудовых обязанностей, компетентными являются суды либо по месту причинения вреда, либо по месту жительства лица, имеющего право на возмещение вреда, по выбору пострадавшего. Не является основанием для отмены правильного определения суда и довод частной жалобы о том, что решение Алчевского городского суда Луганской области Украины от 9 апреля 2001 года ОАО «Дукатская горно-геологическая компания» намерено обжаловать в кассационном порядке. В случае отмены указанного решения соответствующим компетентным судом Украины определение Магаданского областного суда может быть пересмотрено по вновь открывшимся обстоятельствам в соответствии с п. 4 ст. 333 ГПК РСФСР».

Решением Липоводолинского суда Сумской области Республики Украина от 7 октября 2002 года постановлено взыскать с ОАО «Ямалгазпромстрой» в пользу М. утраченный заработок в связи с повреждением здоровья за период с 26 июля 2000 года по 11 марта 2002 года. Определением суда Ямало-Ненецкого автономного округа от 8 мая 2003 года в принудительном исполнении решения Липоводолинского суда Сумской области Республики Украина от 7 октября 2002 г. о возмещении 
ущерба, причиненного повреждением здоровья на территории Российской Федерации, отказано.

Отменяя указанный выше судебный акт и направляя дело на новое рассмотрение, Верховный Суд РФ в Определении от 16 сентября 2003 года по делу № 70-Г03-4117 обратил внимание на следующие нарушения норм международного права. «В соответствии со ст. 55 Конвенции о правовой помощи и правовых отношениях по гражданским, семейным и уголовным делам от 7 октября 2002 г. в признании судебного решения или разрешении исполнения может быть отказано, если согласно положениям настоящей Конвенции, а в случаях, не предусмотренных ею, согласно законодательству Договаривающейся Стороны, на территории которой должно быть признано и исполнено судебное решение, дело относится к исключительной компетенции ее учреждений юстиции. Отказывая в удовлетворении заявленного ходатайства, суд ссылался на названную Конвенцию, считая, что ею определено, что дела о возмещении вреда, причиненного истцу трудовым увечьем, компетентны рассматривать суды того государства, на территории которого имело место причинение вреда или на территории которого находится ответчик. Между тем с таким выводом нельзя согласиться, поскольку согласно ст. 8 Соглашения о взаимном признании прав на возмещение вреда, причиненного работникам увечьем, профессиональным заболеванием либо иным повреждением здоровья, связанным с исполнением ими трудовых обязанностей, от 9 сентября 1994 г. (вступила в силу 6 октября 1995 г.) по делам, предусмотренным в настоящем Соглашении, компетентен суд Стороны, на территории которой имело место действие, послужившее основанием для требования о возмещении вреда, или суд Стороны, на территории которой проживают лица, имеющие право на возмещение вреда, по выбору пострадавшего. Как видно из дела, несчастный случай на производстве произошел 20 июня 1997 г. в поселке Ямбург Надымского района Ямало-Ненецкого автономного округа, местом нахождения организации является г. Надым Ямало-Ненецкого автономного округа. Однако пострадавший проживает на Украине и в качестве компетентного суда правомерно выбрал суд Украины».

Некоторые аспекты права на здоровье конкретизируются в документах Парламентской ассамблеи Совета Европы. Так, в Рекоменда-

${ }^{17}$ Настоящий судебный документ опубликован не был. См. архив Верховного Суда РФ. 
ции 779 (1976) «О правах больных и умирающих» ${ }^{18}$ Ассамблея обратила внимание на то, что право на здоровье тесно связывается с такими основными правами, как право на личное достоинство и право на неприкосновенность, осуществление которых в области здравоохранения порождает определенные проблемы в связи с прогрессом медицинской науки. В Рекомендации особо отмечается, что обязанностью медицинских работников является обслуживание людей, защита их здоровья, лечение болезней и их последствий, уменьшение страданий исходя из уважения человеческой жизни в целом и жизни каждого человека в отдельности, однако продление жизни само по себе не является исключительной целью оказания медицинской помощи. Вместе с тем врачи не имеют права даже в самых безнадежных случаях преднамеренно ускорять естественное наступление смерти.

Ассамблея обратила внимание правительств государств - членов Совета Европы на необходимость:

- обучения медицинского персонала и организации медицинских услуг таким образом, чтобы гарантировать всем нуждающимся получение эффективной медицинской помощи с учетом современного уровня медицинских знаний;

- соблюдения гарантий осуществления права больного на получение полной информации о своей болезни;

- обучения специального персонала для оказания необходимой, в том числе психологической, помощи людям, приближающимся к концу жизни;

- образования на национальном уровне комиссий, в компетенцию которых, в частности, входит определение этических правил в отношении лечения умирающих, а также медицинских принципов, связанных с применением экстраординарных мер для продления жизни и рассмотрением жалоб по поводу ошибок и небрежности при осуществлении медицинской помощи.

Принципы и методы защиты достоинства и прав безнадежно больных и умирающих закрепляются в Рекомендации 1418 (1999) ${ }^{19}$. В этой Рекомендации содержится призыв к государствам - членам Совета Ев-

18 Parliamentary Assembly. Recommendation 779 (1976) on the Rights of the Sick and Dying. Text adopted by the Assembly on 29 January 1976 (24th Sitting).

19 Parliamentary Assembly. Recommendation 1418 (1999). Protection of the Human Rights and Dignity of the Terminally Ill and the Dying. Text adopted by the Assembly on 25 June 1999 (24th Sitting). 
ропы обеспечить в своем национальном праве юридическую и социальную защиту безнадежно больным и умирающим и не допустить невнимательного отношения к ним, того, чтобы их уход из жизни сопровождался невыносимыми страданиями и этот процесс продлевался вопреки их желанию, а кроме того - призыв бороться с ограниченностью доступа к жизнеобеспечивающему лечению в связи с экономическими причинами, недостаточностью фондов и ресурсов для адекватного ухода за такими пациентами.

Реализация прав человека в сфере охраны здоровья, хотя и гарантируется нормами международного права, зависит в первую очередь от степени развития национальной системы здравоохранения, в том числе от уровня ее нормативно-правового, организационного и финансового обеспечения. Доступ к медико-социальной помощи, к информационным ресурсам в области здоровья и здравоохранения, система обеспечения лекарственными средствами - все это напрямую связано с расходами, закладываемыми в бюджет национальных правительств на систему здравоохранения. Очевидно, что государства сильно различаются по уровню национального богатства, но даже в развитых странах Запада средств, предусмотренных бюджетом, зачастую не хватает для покрытия расходов, связанных с медицинским обслуживанием всех групп и слоев населения. Вместе с тем, одним из принципов международно-правовых норм, гарантирующих права человека в области здоровья, является принцип универсального охвата.

Всемирная организация здравоохранения определяет ${ }^{20}$ универсальный охват как доступ к ключевым видам помощи в сфере укрепления здоровья, профилактики, лечения и реабилитации для всех людей по доступным ценам. Тем самым должна обеспечиваться справедливость с точки зрения доступа. Одновременно должен соблюдаться и принцип защиты от финансового риска, означающий, что расходы на медико-санитарную помощь не должны приводить к тому, что люди окажутся на грани финансовой катастрофы. Универсальный охват соответствует принятым ВОЗ концепциям «здоровья для всех» и первичной медико-санитарной помощи.

Реализация универсального охвата зависит от организационных механизмов, которые должны давать возможность вносить финансовый вклад в систему здравоохранения на эффективной и справедливой

20 См.: Предварительная повестка дня 115-й сессии ВОЗ от 2 декабря 2004 г. № $\mathrm{EB} 115 / 8$ 
основе из различных источников. Они должны объединять эти вклады, с тем чтобы риск, связанный с необходимостью платить за медико-санитарное обслуживание, распределялся на всех и не ложился бременем на одного больного, использовать эти вклады в целях обеспечения или приобретения эффективных медико-санитарных услуг. Эффективность и справедливость систем финансирования расходов на охрану здоровья зависит от того, каким способом страны комбинируют эти функции.

Подводя итог всему вышесказанному, хотелось бы попытаться дать исчерпывающее определение праву человека на здоровье, которое учитывало бы вышеприведенные положения международных документов. По мнению автора, оно может выглядеть следующим образом: «Каждый человек без различия расы, религии, политических убеждений, экономического и социального положсения имеет право на наивысший достижимый уровень здоровья, которое характеризуется не только и не столько отсутствием болезней или физических дефектов, сколько состоянием полного физического, душевного и социального благополучия. При этом каждый имеет право на такой жизненный уровень, включая пищу, одежду, жилище, окружаюцую среду, качественный и доступный в экономическом и географическом смысле медицинский уход и соответствующее социальное обслуживание, которое необходимо для обретения и поддержания указанного состояния". 


\section{International Law Regulation of the Right for Health. \\ (Summary)}

Viktoria G. Borisova-Zharova*

Effective protection of the right to health from the viewpoint of law is possible only if there is an efficient mechanism of the realization of norms, which regulate the relations in this sphere. As the problems of healthcare has transcended the national borders and now have a universal character the international law has elaborated a system of rules, standards and prescriptions the aim of which is to resolve international problems in the sphere of healthcare.

In the article international documents related to the issue and the practice of IHO are analyzed as the provisions of international acts regulate various problems in the sphere of healthcare and the practice of international organizations assist in their implementation. This forms the basis for a new international law institute of human right to health to emerge.

The author suggests in the article the complete definition of human right to health on the basis of the provisions of international documents which runs as follows: "Each person without distinction of race, religion, political convictions, economic and a social status has the right to the highest achievable level of health which is characterized not only and not so much absence of illnesses or physical defects, but a condition of full physical, sincere and social well-being. Thus everyone has the right to such standard of life, including food, clothes, dwelling, environment, qualitative and accessible in economic and geographical sense medical leaving and necessary social service which is necessary for find and maintain the specified condition."

* Viktoria G. Borisova-Zharova - post-graduate student of the Chair of International law of the Diplomatic Academy MFA Russia. 